\title{
Ocular allergy therapy perspectives: Review on the main therapeutic targets
}

\author{
Perspectivas no tratamento da alergia ocular: \\ Revisão das principais estratégias terapêuticas
}

Leda das Neves Almeida Sandrin', Ruth Miyuki Santo²

\begin{abstract}
Ocular allergies encompass a number of inflammatory diseases in the ocular surface which have different hypersensitivity mechanisms and occur in $20 \%$ of population. They can be classified as being type I hypersensitivity mediated (PAC, SAC), type I and IV (VKC, $A K C)$ and type $I V(B K C, G P C)$. The most prevalent forms are PAC and SAC. The chronic presentations are mostly related to visual impairment due to remodeling in the ocular surface caused by chronic inflammation. Dry eye disease and keratoconus are comorbidities observed in severe cases. The management is based on accurate diagnosis, avoidance of etiological factors and the rational use of drugs that control the inflammatory events caused by Th2 driven. The advances in knowledge on activation and traffic of immune cells are providing new drugs and many perspectives on different approaches.
\end{abstract}

Keywords: Conjunctivitis, allergic/physiopathology; Conjunctivitis, allergic/drug therapy; keratoconjunctivitis; Drug hypersensitivity; Hypersensitivity, immediate; Immunoglobulin E

\section{RESUMO}

As alergias oculares englobam uma série de doenças inflamatórias da superfície ocular, causadas por diferentes mecanismos de hipersensibilidade. Acometem aproximadamente $20 \%$ da população e podem ser classificadas em formas mediadas por hipersensibilidade tipo I (CAS, CAP), tipo I e IV (CCV, CCA) e tipo IV (BCC, CPG). As formas mais prevalentes são CAS e CAP. As formas crônicas (CCV, CCA), estão mais frequentemente relacionadas a complicações e comprometimento da função visual decorrentes do processo inflamatório e consequente remodelação da superfície ocular. Comorbidades como olho seco e ceratocone podem estar presentes. O tratamento envolve diagnóstico e afastamento dos fatores etiológicos envolvidos, uso de drogas antiinflamatórias que atuem na ação de linfócitos Th2, eosinófilos, mastócitos e células dendríticas Avanços no conhecimento da ativação e tráfego de células do sistema imune têm sido promissores na perspectiva de novas abordagens terapêuticas.

Descritores: Conjuntivite alérgica/fisiopatologia; Conjuntivite alérgica/quimioterapia; Ceratoconjuntivite Hipersensibilidade a drogas; Hipersensibilidade imediata; Imunoglobulina E

\footnotetext{
1 Post-graduate program, Faculdade de Medicina Universidade de São Paulo, São Paulo, SP, Brazil.

2 Faculdade de Medicina Universidade de São Paulo, São Paulo, SP, Brazil.

Institution: Faculdade de Medicina da Universidade de São Paulo, São Paulo, SP, Brazil.
}

The authors declare no conflicts of interest

Received for publication 27/08/2014 - Accepted for publication 14/10/2014 


\section{INTRODUCTION}

\section{CLINICAL PROFILE OF EYE ALLERGY}

$\mathbf{E}$ ye Allergy refers to a heterogeneous group of allergic diseases of the eye surface whose cardinal symptom is pruritus. Epidemiological studies on the prevalence and incidence of eye allergy are conflicting due to the difficulties in standardization of nomenclature and diagnosis ${ }^{(1)}$, as well as due to the questionnaires prioritize the term allergic rhinoconjunctivitis and in most cases do not use specific questions about eye allergy isolatedly ${ }^{(2)}$. In general, a high prevalence $(20 \%)^{(2)}$ is observed. Although responsible for the decrease in quality of life in a significant number of patients both by the hassle of symptoms or the complications of it, it is still an underdiagnosed disease, and self-medication is frequent ${ }^{(4)}$. Studies show that few patients are evaluated by expert ophthalmologists and/or allergists $^{(4)}$. However, severe cases $(2 \%)^{(5)}$ generally go to specialized services, which may be responsible for their high prevalence in some studies ${ }^{(6)}$.

Mild forms account for about $98 \%$ of cases $^{(5)}$, and are characterized by two syndromes: A perennial allergic conjunctivitis (PAC) and seasonal allergic conjunctivitis (SAC), often associated to other systemic allergic diseases such as allergic rhinitis, asthma and atopic dermatitis. The perennial form is associated to environmental allergens such as mites, cockroaches, animal epithelia and fungi. The seasonal foorm occurs predominantly in southwestern Brazil from August to December, and relates to the exposure and sensitization to airborne vegetable allergens, especially grass pollen ${ }^{(7-8)}$. The main symptoms are itchy eyes, conjunctival hyperemia, tearing and conjunctival edema and/or chemosis, and corneal ulcerations may rarely occur due to the continuous itching. The seasonal form tends to be more intense due to the unavoidable exposure to aeroallergens, and PAC patients may present chronic conditions getting seasonally worse due to the polysensitization.

Chronic and severe forms, although rare, can be devastating. They are divided into two groups: vernal keratoconjunctivitis (VKC) and atopic keratoconjunctivitis (AKC). In such cases, inflammation mediated by type 1 hypersensitivity with $\mathrm{IgE}$ production may or may not be present, although the inflammatory effect arising from the infiltration and activation of eosinophils and lymphocytes resulting from type IV hypersensitivity always occur.

Atopic keratoconjunctivitis (AKC) usually affects adult patients from the third and fourth decades and patients with atopic dermatitis since childhood. Advanced cases of AKC occur with sub-epithelial fibrosis, symblepharon, buds, corneal ulceration, neovascularization, decreased goblet cells and occasionally cataracts. The main symptoms include intense itching, photophobia, burning sensation and foreign body. The main findings in clinical examination are buds on the upper and lower tarsus, injection and conjunctival edema, atopic dermatitis on the eyelids, puntata corneal erosions and shield ulcer.

VKC takes place in the first and second decades of life, and is prevalent in boys (3/1) and usually disappears in adulthood ${ }^{(9)}$. It may be with or without atopy. It has two main forms, the limbic one with Horner Trantas nodules and limb edema, and the tarsal form with tarsal buds, and bith forms may coexist. The main symptoms are itching, photophobia, mucous secretion, conjunctival hyperemia and pain associated to corneal lesions.

The BCC is an inflammatory process caused by type IV hypersensitivity, secondary to the contact dermatitis caused by haptens applied to the conjunctiva and/or eyelid. BCC may coexist associated to other forms of conjunctivitis and even be caused by hypersensitivity due to allergy to the active ingredients and preservatives present in eyedrops.

CPG is caused by the continuous trauma between the conjunctiva and contact lenses, leading to an inflammation mediated by cells of the innate immune system and the formation of giant buds on the upper tarsus.

\section{Pathophysiology}

The pathophysiology of eye allergy is associated to the inflammatory response generated by types I and IV hypersensitivity mechanisms characteristic of the activation actions of the subtype of Th2 lymphocytes, mast cells and eosinophils ${ }^{(5-10)}$. Some studies have shown the activation of lymphocyte subtypes Th1 in $\mathrm{CCA}^{(6)}$. Thus, genetically predisposed patients and exposed to various environmental allergens can initiate the allergic response by the antigen processing performed by non-lymphoid dendritic cells (DC) present in eye surface. Once the antigen (allergen) is processed, the dendritic cell is activated and initiates the release of inflammatory interleukins as the factor of tumor necrosis , IL-1 and IL-6 as well as increased surface protein expression (CCR7, MHC-II ), important for the migration to peripheral lymph organs and antigen presentation to $\mathrm{Th} 0$ lymphocytes via MHC II (major histocompatibility complex) ${ }^{(10)}$.

After antigen recognition, Th0 lymphocytes change into Th2 cells producing IL-4, IL-5 and IL-13, which are the interleukins responsible for the activation and transformation of B lymphocytes into plasma cells producing IgE. Once produced, the specific IgE circulates and binds to high affinity receptors present on the membrane of the mast cells of the eye surface, making them sensitized ${ }^{(10)}$.

During the antigen rechallenge, the sensitized mast cells degranulate by destabilization of the membrane caused by the crosslinking of $\operatorname{IgE}$, releasing pre-formed mediators such as histamine and tryptase clinically causing the symptoms of itching, edema, and hyperemia after binding to the histamine receptors. This is a response which occurs rapidly after the exposure to the allergen, and lasts about 30 minutes. After the release of preformed granules, the arachidonic acid metabolism activation via phospholipase $\mathrm{A} 2$ in the membrane of mast cells leads to the production of prostaglandins and leukotrienes, responsible for the late response, 4 to 6 hours after the initial response, with reappearance of inflammatory symptoms and infiltration of neutrophils and eosinophils ${ }^{(5)}$.

It is important to remember that currently four types of histamine receptors $(\mathrm{H} 1, \mathrm{H} 2, \mathrm{H} 3$ and $\mathrm{H} 4)$ are known and distributed in different cells and with different biological functions ${ }^{(11)}$. Special attention must be given to the $\mathrm{H} 4$ receptors responsible for the activation / modulation of the innate immune system cells such as epithelial cells, NK cells, antigen presenting cells and eosinophils ${ }^{(11)}$.

Interleukins IL-4, IL-5, IL-6, IL-8, IL-13 produced by Th2 lymphocytes and activated TC mast cells present on the eye surface favor the maturation, migration, and activation of eosinophils ${ }^{(12-13)}$. The eosinophilic inflammation causes tissue damage through a variety of proteins released as cationic protein, most basic protein, peroxidase and neurotoxin, and is responsible for the remodeling of the eye surface and maintenance of the symptoms in chronic conjunctivitis ${ }^{(10-14)}$. Interleukins associated to Th1 stimulus (factor of tumor necrosis and interferon gamma) 
as proposed to the pathophysiology of AKC, may be associated to a decreased function of the goblet cells and consequent changes in the eye surface and the dry eye syndrome observed in these patients. Severe forms of allergy (AKC, VKC) may present inflammation mediated by lymphocytes, neutrophils and eosinophils without increasing serum IgE or eye surface, characterizing a hypersensitivity inflammation of type $\mathrm{IV}^{(15)}$.

The immune process described above can be presented with varying intensities due to environmental and genetic factors involved in the production of different subtypes of cytokines responsible for maintaining the inflammatory activity. The determination of cytokine levels in tears and the genetic analysis of protein expression in the eye surface cells of the eyes affected by allergic conjunctivitis show the phenotypic difference in different clinical presentations ${ }^{(16-17)}$.

\section{AsSOCIATED COMPLICATIONS}

Keratoconus and dry eye are complications that may be associated to or be made worse by inflammation of the eye surface and the continuous itching, which is key in the early diagnosis and guidance in these cases ${ }^{(18)}$. The frequent association between keratoconus with atopy and chronic ocular itching has been described $^{(19)}$, and early development of keratoconus in patients with VKC has been observed ${ }^{(20)}$. Frequent use of electronic devices associated to the high number of allergic conjunctivitis cases may be related to the high prevalence of dry eye syndrome found in the studies ${ }^{(21-22)}$.

\section{TREATMENT}

The main goals of the treatment are reducing the symptoms and minimizing the complications by controlling the inflammatory process through preventive, pharmacological and environmental measures. It should be noted that allergic diseases of the eye surface need to be addressed by a multidisciplinary team ${ }^{(23)}$ mainly involving ophthalmologists and allergists, and ocular and systemic comorbidities must be promptly diagnosed and treated.

Mild allergic conjunctivitis are the most frequent ones and generally mediated by IgE, and therefore their treatment depends on the etiologic diagnosis that can be accomplished by skin tests with immediate reading, specific serum IgE tests or conjunctival provocation with allergens ${ }^{(9-24)}$. In unwieldy chronic cases, a multidisciplinary approach can add new therapeutic modalities in controlling inflammation.

\section{Lubricants}

They may be indicated to increase the clearance of allergens on the eye surface and control the disorder of the tear film. Where possible these lubricants must be free from preservatives, as they can cause epithelial toxicity or even allergies, as in the case of benzalkonium chloride ${ }^{(25)}$.

\section{Antihistamines}

Topic antihistamines in the form of eyedrops are indicated for the relief of symptoms, and act by blocking the histamine action on their receptors, particularly in the $\mathrm{H} 1$ receptors. Emedastine and levocabastine are examples of this group of drugs. These drugs act in the immediate phase of the inflammatory process, and do not prevent the release of mediators from the arachidonic acid. The need for frequent use leads to poor adherence. They can cause mydriasis and cycloplegia, as they may interact with muscarinic and alpha adrenergic receptors receptors, and caution is required in the use in patients at risk of angle-closure glaucoma ${ }^{(9-25)}$.

\section{Membrane stabilizers}

This group of drugs such as sodium cromoglycate 2 or $4 \%$ acts by stabilizing the mast cell membranes by blocking the calcium channels preventing the release of histamine and activating the membrane enzymes, and thus decreasing the inflammatory response and infiltration of inflammatory cells such as eosinophils, neutrophils and lymphocytes. The onset of action is slow, about seven to fifteen days ${ }^{(25)}$, and should be reapplied several times a day, which can lead to poor adhesion due to the discomfort and risk of eye irritation. They can be used in all types of allergic conjunctivitis ${ }^{(9)}$.

\section{Double-action drugs}

Double-action, antihistaminic and membrane-stabilizing topical drugs are widely used and able to reduce the immediate response by blocking the $\mathrm{H} 1$ receptors as well as the delayed response by stabilizing the membrane of mast cells with subsequent inhibition of activation and chemotaxis of eosinophils. Among the main drugs of this group are ketotifen, epinastine, and olopatadine ${ }^{(26)}$ and alcaftadine. Small variability in the mechanism and time of action between these drugs has been described. Comparative studies in animal and humans models between olopatadine and alcaftadine show a more prolonged effect on the control of itching, and a decreased recruitment of eosinophils using the alcaftadine $0.25 \%$, probably related to its action on $\mathrm{H} 4$ receptor ${ }^{(27-28)}$. They are relatively safe drugs, but may cause adverse effects resulting from the action on muscarinic and alpha adrenergic receptors, and should be used with caution in patients with narrow angle. Suitable for all types of allergic conjunctivitis, they are well tolerated, and presentations of daily use only favor adhesion to the treatment ${ }^{(26-27-29)}$.

\section{Corticosteroids}

The use of topical corticosteroids is quite effective in reducing the entire inflammatory cascade of the allergic process, especially in chronic forms of allergic conjunctivitis. However, prolonged use is associated to several complications such as increased intraocular pressure and glaucoma, cataracts and more prone to eye infections, including herpetic keratitis ${ }^{(30)}$. Corticosteroids act by binding to cytosolic glucocorticoid receptors (GR). These complexes act at genomic level by decreasing the production of several inflammatory cytokines. The non-genomic effects of this complex and the direct action of glucocorticoids on cell membranes are also described. With these actions there is an inhibition of cell infiltration and fibroblast proliferation, stabilization of intra and extra cellular membranes, blocking of A2 phospholipase and subsequent inhibition of production of membrane metabolites with inflammatory actions, increased production of histaminase and decreased production of histamine. There are several topical presentations of corticosteroids like dexamethasone, fluormetolone, rimexolone, prednisolone and loteprednol ${ }^{(31-32)}$.

Loteprednol etabonate is a new topical steroid with structural modifications where the ketone group at carbon 20 is replaced by an ester group. This modification increases the metabolism and decreases the formation of covalent bonds with proteins of the crystalline, thereby reducing the risk of cataract 
formation and increased intraocular pressure. These aspects are proven in several studies ${ }^{(31,33)}$.

Topical corticosteroids are indicated in chronic forms of unwieldy allergic conjunctivitis and acute forms in selected cases ${ }^{(33)}$.

\section{Immunomodulators}

The effect of immunomodulators on the eye surface has been extensively studied in inflammatory diseases as an alternative to topical corticosteroids due to side effects thereof and the lack of control in some cases of severe allergic conjunctivitis (AKC, VKC). Cyclosporine and tacrolimus are the main drugs of this group. The mechanism of action of these drugs called calcineurin inhibitors occurs via inhibition of the IL-2 receptors present on $\mathrm{T}$ lymphocytes and responsible for the activation $^{(34)}$.

A recently published study demonstrates that the prolonged use of tacrolimus in the form of $0.1 \%$ dermatological ointment is safe and effective in treating patients with AKC refractory to conventional treatment, thus demonstrating to be an alternative in the substitution of topical corticosteroids. In this same study, the case of a patient with severe AKC is described, which became blind due to glaucoma acquired by topical corticosteroids and showed significant improvement of AKC after the use of topical tacrolimus ${ }^{(35)}$. Comparative studies between ciclosporin $2 \%$ and tacrolimus $0.1 \%$ applied topically to severe cases of ocular allergy show similar effectiveness; however, the burning sensation is more evident with the use of cyclosporin ${ }^{(36)}$. Cyclosporin in a dose of $0.05 \%$ is similar to the placebo in serious ocular allergy conditions ${ }^{(37)}$, perhaps this being an inadequate concentration to treat severe forms. Moreover, studies showed good response with the use of topical tacrolimus $0.03 \%{ }^{(38)}$. Regarding the time and manner of use, studies show that tacrolimus $0.03 \%$ and $0.1 \%$ may be applied twice a day at the beginning of the treatment, and then reduced to a single daily use or even two to three times a week to maintain the control of symptoms and the inflammatory process $^{(35-38-39)}$. Despite the favorable findings of the action of these drugs in controlling allergic inflammation, further studies are needed to understand the safety profile and the actions and potential long-term side effects ${ }^{(9-25-32-40-41)}$.

\section{Anti-IgE}

Omalizumab is a monoclonal humanized anti-IgE antibody (IgG1) that binds to free circulating IgE (blood and interstitial fluid) and B lymphocyte membrane IgE, thus controlling the inflammatory process mediated hypersensitivity type I. It is indicated in cases of severe asthma and spontaneous chronic urticaria in patients older than 12 years ${ }^{(42)}$. The route of administration is subcutaneous, and it should be performed under medical supervision in the hospital. Doses may be monthly or weekly. Reports on the use of omalizumab in severe cases of $\mathrm{AKC}$ and $\mathrm{VKC}$ with improvement were published. This is a costly, not available in many places, not approved medication for exclusive use in cases of allergic conjunctivitis. Side effects include headache and rarely anaphylaxis ${ }^{(43)}$.

\section{Specific Immunotherapy: Sublingual and Injection}

The specific immunotherapy is a treatment based on the application of the allergen to which the patient is sensitized at increasing and continuous doses. There are two main types of application: oral and subcutaneous. This treatment modality should be practiced in patients with IgE-mediated disease proven in vivo or in vitro by skin tests with immediate reading or serum dosage of specific IgE. It is a long treatment with proven efficacy which induces immunological tolerance specifically to the allergen used ${ }^{(4-46)}$. A recent randomized double-blind clinical study shows the efficacy of sublingual immunotherapy with Artemisia pollen in patients presenting allergic rhinoconjunctivitis ${ }^{(47)}$.

\section{Prospects in the treatment}

\section{Rebamipide}

Rebamipide is a gastroprotective drug that increases gastric mucus secretion and decreases the inflammatory process $^{(48)}$. In Japan, the presentation in the form of eyedrops $2 \%$ was approved for the treatment of dry eye syndrome. Rebamipide increases the mucin secretion, and the antiinflammatory action on the eye surface occurs by the inhibition of the activity of tumor necrosis factor alpha on the production of IL- 6 and IL- 8 cytokines and the protection of the zonula occludens with subsequent maintenance of the corneal epithelial cytoskeleton. An experimental model of allergic conjunctivitis was able to reduce the infiltration of eosinophils ${ }^{(48)}$. A recent study showa a decrease of giant buds significant symptom improvement with the use of rebamipide $2 \%$ eyedrops in patients with $\mathrm{VKC}$ and/or AKC refractory to conventional pharmacological treatment with symptoms of decreased dry eye and time of tear film breakup ${ }^{(49)}$. Although further studies are needed, the use of rebamipide looks promising in the treatment of eye allergy.

\section{Anti-CCR7}

Dendritic cells have been extensively studied as a therapeutic target in many diseases. They are responsible for the antigen presentation to $\mathrm{T}$ lymphocytes and the secretion of various cytokines that cause the transformation of T lymphocytes in different subtypes of lymphocytes (Th1, Th2, Th17, Treg). Studies have demonstrated the predominance of non-lymphoid dendritic cells, CD11b+ in the ocular conjunctiva ${ }^{(50)}$. The process of recognition, antigen processing and presentation of them to lymphocytes via dendritic cells depends on chemokines and their respective ligands. CCR7 is a surface protein expressed in activated dendritic cells and responsible for their traffic to the peripheral lymphoid organs (where there is the presentation of antigens) via their ligands CCL19/CCL21 present on the endothelial surface and lymphatic vessels. Interestingly, after activation, the dendritic cell itself expresses ligands for CCR7 and the Th0 lymphocytes also express CCR7, favoring the encounter between the cells for antigen presentation. Thus, the CCR7 molecule contributes to the antigen-presenting cell traffic, as well as the persistence of memory Th2 cell activation ${ }^{(10)}$. The therapeutic opportunity for use of anti-CCR7 on the eye surface consists in the possibility of blocking the output of dendritic cells from the eye tissue to the peripheral lymphoid organs. An experimental model of allergic conjunctivitis in guinea pigs demonstrates that the use of anti-CCR7 was able to clinically reduce the signs of allergic conjunctivitis as well as reduce Th2 response and eosinophilic infiltration in the eye surface ${ }^{(51)}$.

\section{ConcLusion}

The ocular allergy conditions, though frequent, are undiagnosed. Detailed studies on the immunology of the eye 
surface have favored the development of new therapeutic strategies, as well as the rational use of safer and more effective drugs in severe cases. However, it should be noted the need for further and deeper epidemiological studies, as well as the importance of a multidisciplinary approach to the early diagnosis and the adequate treatment.

\section{REFERENCES}

1. Santos MS,Alves MR, Freitas Dd, Sousa LB, Wainsztein R, Kandelman $\mathrm{S}$, et al. Ocular allergy latin american consensus. Arq Bras Oftalmol. 2011;74(6):452-6.

2. Rosario N, Bielory L. Epidemiology of allergic conjunctivitis. Curr Opin Allergy Clin Immunol. 2011;11(5):471-6.

3. Trocme SD, Sra KK. Spectrum of ocular allergy. Curr Opin Allergy Clin Immunol. 2002;2(5):423-7.

4. Blaiss MS, Dykewicz MS, Skoner DP, Smith N, Leatherman B, Craig TJ, et al. Diagnosis and treatment of nasal and ocular allergies: the Allergies, Immunotherapy, and RhinoconjunctivitiS (AIRS) surveys. Ann Allergy Asthma Immunol. 2014;112(4):322-8.

5. Ono SJ,Abelson MB. Allergic conjunctivitis: update on pathophysiology and prospects for future treatment. J Allergy Clin Immunol. 2005;115(1):118-22.

6. Marback PM, de Freitas D, Paranhos Junior A, Belfort Junior R. [Epidemiological and clinical features of allergic conjunctivitis in a reference center]. Arq Bras Oftalmol. 2007;70(2):312-6. Portuguese

7. Taketomi EA, Sopelete MC, Moreira PF, Vieira FA. Doença alérgica polínica: polens alergógenos e seus principais alérgenos. Rev Bras Otorrinolaringol. 2006;72:562-7.

8. Vieira FA, Ferreira EN, Cruz AA. Grass allergy increases the risk of tree pollen sensitization: a warning to urban planners. J Allergy Clin Immunol. 1998;102(4 Pt 1):700-1.

9. Leonardi A, Bogacka E, Fauquert JL, Kowalski ML, Groblewska A, Jedrzejczak-Czechowicz M, et al. Ocular allergy: recognizing and diagnosing hypersensitivity disorders of the ocular surface. Allergy. 2012;67(11):1327-37.

10. Saban DR. The chemokine receptor CCR7 expressed by dendritic cells: a key player in corneal and ocular surface inflammation. Ocul Surf. 2014;12(2):87-99.

11. O'Mahony L,Akdis M,Akdis CA. Regulation of the immune response and inflammation by histamine and histamine receptors. J Allergy Clin Immunol. 2011;128(6):1153-62.

12. Siddique M, Manzouri B, Flynn TH, Ono SJ.Allergy and contact lenses. Chem Immunol Allergy. 2007;92:166-75.

13. Hodges MG, Keane-Myers AM. Classification of ocular allergy. Curr Opin Allergy Clin Immunol. 2007;7(5):424-8.

14. Vichyanond P, Pacharn P, Pleyer U, Leonardi A. Vernal keratoconjunctivitis: a severe allergic eye disease with remodeling changes. Pediatr Allergy Immunol. 2014 ;25(4):314-22.

15. Contreras-Ruiz L, Ghosh-Mitra A, Shatos MA, Dartt DA, Masli S. Modulation of conjunctival goblet cell function by inflammatory cytokines. Mediators Inflamm. 2013;2013:636812.

16. Leonardi A, Curnow SJ, Zhan H, Calder VL. Multiple cytokines in human tear specimens in seasonal and chronic allergic eye disease and in conjunctival fibroblast cultures. Clin Exp Allergy. 2006;36(6):777-84.

17. Leonardi A. Allergy and allergic mediators in tears. Exp Eye Res. 2013;117:106-17.

18. Sharma N, Rao K, Maharana PK, Vajpayee RB. Ocular allergy and keratoconus. Indian J Ophthalmol. 2013;61(8):407-9.

19. Weed KH, MacEwen CJ, Giles T, Low J, McGhee CN. The Dundee University Scottish Keratoconus study: demographics, corneal signs, associated diseases, and eye rubbing. Eye (Lond). 2008;22(4):53441.

20. Dantas PE, Alves MR, Nishiwaki-Dantas MC. Topographic corneal changes in patients with vernal keratoconjunctivitis. Arq Bras Oftalmol. 2005;68(5):593-8.

21. Kim TH, Moon NJ. Clinical correlations of dry eye syndrome and allergic conjunctivitis in Korean children. J Pediatr Ophthalmol Strabismus. 2013;50(2):124-7.

22. Moon JH, Lee MY, Moon NJ. Association between video display terminal use and dry eye disease in school children. J Pediatr Ophthalmol Strabismus. 2014:51(2):87-92.

23. Bielory L. Ocular allergy. Mt Sinai J Med. 2011;78(5):740-58.

24. Abelson MB, Loeffler O. Conjunctival allergen challenge: models in the investigation of ocular allergy. Curr Allergy Asthma Rep. 2003;3(4):363-8.

25. Bielory L, Meltzer EO, Nichols KK, Melton R, Thomas RK, Bartlett JD. An algorithm for the management of allergic conjunctivitis. Allergy Asthma Proc. 2013;34(5):408-20.

26. Dogru M, Ozmen A, Erturk H, Sanli O, Karatas A. Changes in tear function and the ocular surface after topical olopatadine treatment for allergic conjunctivitis: an open-label study. Clin Ther. 2002;24(8):1309-21.

27. Ono SJ,Lane K. Comparison of effects of alcaftadine and olopatadine on conjunctival epithelium and eosinophil recruitment in a murine model of allergic conjunctivitis. Drug Des Devel Ther. 2011;5:77-84.

28. Ackerman S, D'Ambrosio F, Jr., Greiner JV, Villanueva L, Ciolino JB, Hollander DA. A multicenter evaluation of the efficacy and duration of action of alcaftadine $0.25 \%$ and olopatadine $0.2 \%$ in the conjunctival allergen challenge model. J Asthma Allergy. 2013;6:43-52.

29. Greiner JV, Edwards-Swanson K, Ingerman A. Evaluation of alcaftadine $0.25 \%$ ophthalmic solution in acute allergic conjunctivitis at 15 minutes and 16 hours after instillation versus placebo and olopatadine 0.1\%. Clin Ophthalmol. 2011;5:87-93.

30. Bonini S, Bonini S, Lambiase A, Marchi S, Pasqualetti P, Zuccaro O, et al. Vernal keratoconjunctivitis revisited: a case series of 195 patients with long-term followup. Ophthalmology. 2000;107(6):1157-63.

31. Comstock TL, Decory HH. Advances in corticosteroid therapy for ocular inflammation: loteprednol etabonate. Int J Inflam. 2012;2012:789623.

32. Mantelli F, Calder VL, Bonini S. The anti-inflammatory effects of therapies for ocular allergy. J Ocul Pharmacol Ther. 2013;29(9):786-93.

33. Gong L, Sun X, Qu J, Wang L, Zhang M, Zhang H, et al. Loteprednol etabonate suspension $0.2 \%$ administered QID compared with olopatadine solution $0.1 \%$ administered BID in the treatment of seasonal allergic conjunctivitis: a multicenter, randomized, investigatormasked, parallel group study in Chinese patients. Clin Ther. 2012;34(6):1259-72 e1.

34. Tzu JH, Utine CA, Stern ME, Akpek EK. Topical calcineurin inhibitors in the treatment of steroid-dependent atopic keratoconjunctivitis. Cornea. 2012;31(6):649-54.

35. Al-Amri AM. Long-term follow-up of tacrolimus ointment for treatment of atopic keratoconjunctivitis. Am J Ophthalmol. 2014 ;157(2):280-6.

36. Labcharoenwongs $\mathrm{P}$, Jirapongsananuruk O, Visitsunthorn N, Kosrirukvongs P, Saengin P, Vichyanond P. A double-masked comparison of $0.1 \%$ tacrolimus ointment and $2 \%$ cyclosporine eye drops in the treatment of vernal keratoconjunctivitis in children. Asian Pac J Allergy Immunol. 2012;30(3):177-84.

37. Daniell M,Constantinou M,Vu HT,Taylor HR. Randomised controlled trial of topical ciclosporin A in steroid dependent allergic conjunctivitis. Br J Ophthalmol. 2006;90(4):461-4.

38. Kymionis GD, Goldman D, Ide T, Yoo SH.Tacrolimus ointment $0.03 \%$ in the eye for treatment of giant papillary conjunctivitis. Cornea. 2008;27(2):228-9. 
39. Tam PM, Young AL, Cheng LL, Lam PT. Topical tacrolimus $0.03 \%$ monotherapy for vernal keratoconjunctivitis-case series. $\mathrm{Br} \mathrm{J}$ Ophthalmol. 2010;94(10):1405-6.

40. Wan KH, Chen LJ, Rong SS, Pang CP, Young AL. Topical cyclosporine in the treatment of allergic conjunctivitis: a meta-analysis. Ophthalmology. 2013;120(11):2197-203.

41. Erdinest N, Solomon A. Topical immunomodulators in the management of allergic eye diseases. Curr Opin Allergy Clin Immunol. 2014;14(5):457-63.

42. Goldenberg MM. Pharmaceutical approval update. P T. 2014;39(6):41523.

43. de Klerk TA, Sharma V,Arkwright PD, Biswas S. Severe vernal keratoconjunctivitis successfully treated with subcutaneous omalizumab. J AAPOS. 2013;17(3):305-6.

44. Canonica GW, Cox L, Pawankar R, Baena-Cagnani CE, Blaiss M, Bonini $\mathrm{S}$, et al. Sublingual immunotherapy: World Allergy Organization position paper 2013 update. World Allergy Organ J. 2014;7(1):6.

45. Di Bona D, Plaia A, Leto-Barone MS, La Piana S, Di Lorenzo G. Efficacy of subcutaneous and sublingual immunotherapy with grass allergens for seasonal allergic rhinitis: a meta-analysis-based comparison. J Allergy Clin Immunol. 2012;130(5):1097-107 e2.

46. Jacobsen L, Wahn U, Bilo MB. Allergen-specific immunotherapy provides immediate, long-term and preventive clinical effects in children and adults: the effects of immunotherapy can be categorised by level of benefit -the centenary of allergen specific subcutaneous immunotherapy. Clin Transl Allergy. 2012;2:8.

47. Creticos PS, Esch RE, Couroux P, Gentile D, D'Angelo P, Whitlow B, et al. Randomized, double-blind, placebo-controlled trial of standardized ragweed sublingual-liquid immunotherapy for allergic rhinoconjunctivitis. J Allergy Clin Immunol. 2014;133(3): 751-8.

48. Ueta M, Sotozono C, Yokoi N, Kinoshita S. Rebamipide suppresses PolyI:C-stimulated cytokine production in human conjunctival epithelial cells. J Ocul Pharmacol Ther. 2013;29(7):688-93.

49. Ueta M, Sotozono C, Koga A, Yokoi N, Kinoshita S. Usefulness of a new therapy using rebamipide eyedrops in patients with $\mathrm{VKC} / \mathrm{AKC}$ refractory to conventional anti-allergic treatments. Allergol Int. 2014;63(1):75-81.

50. Khandelwal P, Blanco-Mezquita T, Emami P, Lee HS, Reyes NJ, Mathew R, et al. Ocular mucosal CD11b+ and CD103+ mouse dendritic cells under normal conditions and in allergic immune responses. PLoS One. 2013;8(5):e64193.

51. Schlereth S, Lee HS, Khandelwal P, Saban DR. Blocking CCR7 at the ocular surface impairs the pathogenic contribution of dendritic cells in allergic conjunctivitis. Am J Pathol. 2012;180(6):2351-60.

\section{Corresponding author:}

Leda das Neves Almeida Sandrin

Rua Barão do Rio Branco, 300-E, Ed. Policlínica Santo Antônio, room 314

Chapecó-SC. Zip Code: 89802-100

E-mail: ledasandrin@clinicasandrin.com.br 